\title{
The African Surgical OutcomeS-2 (ASOS-2) Pilot Trial, a mixed-methods implementation study
}

\author{
L du Toit, ${ }^{1}$ HL Kluyts, ${ }^{2}$ V Gobin, ${ }^{3}$ CM Sani, ${ }^{4}$ E Zoumenou, ${ }^{5}$ AO Omigbodun, ${ }^{6}$ SD Amanor-Boadu, ${ }^{7}$ S Zimogo, ${ }^{8}$ A Ndonga, ${ }^{9}$ Z \\ Ngumi, ${ }^{10}$ DM Munlemvo, ${ }^{11}$ C Copley, ${ }^{12}$ D van Straaten, ${ }^{13}$ P Forget, ${ }^{14}$ RM Pearse, ${ }^{15}$ BM Biccard
}

on behalf of the African Surgical OutcomeS-2 (ASOS-2) Trial investigators. *See ASOS-2 Pilot Trial Investigators

1. Department of Anaesthesia and Perioperative Medicine, Groote Schuur Hospital, Faculty of Health Sciences, University of Cape Town, South Africa

2. Department of Anaesthesiology, Sefako Makgatho Health Sciences University, South Africa

3. Ministry of Health and Quality of Life, Jawaharlal Nehru Hospital (JNH), Rose Belle, Mauritius

4. Department of Aanesthesiology, Intensive Care and Emergency, National Hospital of Niamey, Republic of Niger

5. Faculté des Sciences de la Santé de Cotonou, Hôpital de la mère et de l'enfant, Lagune de Cotonou, Benin

6. College of Medicine, University of Ibadan, Nigeria

7. Department of Anaesthesia, University College Hospital, Ibadan, Nigeria

8. CHU du POINT G, Mali

9. General and Gastrosurgery, Mater Hospital, Kenya

10. Department of Anaesthesia, University of Nairobi School of Medicine, Kenya

11. University Hospital of Kinshasa, Democratic Republic of Congo

12. Praekelt.org, South Africa

13. Safe Surgery South Africa, South Africa

14. Vrije Universiteit Brussel (VUB), Universitair Ziekenhuis Brussel (UZ Brussel), Anesthesiology and Perioperative Medicine, Belgium

15. Intensive Care Medicine, Queen Mary University of London, United Kingdom, EC1M 6BQ

Corresponding author: Professor Bruce Biccard (bruce.biccard@uct.ac.za)

Background: The African Surgical Outcomes Study (ASOS) showed that surgical patients in Africa have a mortality twice the global average. The working hypothesis is that patients die as a result of failure to rescue following complications in the postoperative period. The African Surgical OutcomeS-2 (ASOS-2) Trial plans to test the efficacy of increased postoperative surveillance in high risk patients for decreasing perioperative morbidity and mortality. This pilot trial aimed i) to evaluate the adequacy of data produced by the data collection strategies of the ASOS-2 Trial, ii) to evaluate the fidelity of implementation of the increased postoperative surveillance intervention, and iii) to understand the acceptability, appropriateness and feasibility of the intervention and the trial processes.

Methods: The ASOS-2 Pilot Trial was a mixed-methods (quantitative-qualitative) implementation study focusing on the intervention arm of the proposed ASOS-2 Trial. The intervention is increased postoperative surveillance for high-risk surgical patients. The intervention protocol was implemented at all sites for a seven-day period. A post pilot trial survey was used to collect data on the implementation outcomes.

Results: 803 patients were recruited from 16 hospitals in eight African countries. The sampling and data collection strategies provided $98 \%$ complete data collection. Seventy-three percent of respondents believed that they truly provided increased postoperative surveillance to high risk patients. In reality $83 / 125(66 \%)$ of high-risk patients received some form of increased postoperative surveillance. However, the individual components of the increased postoperative surveillance intervention were implemented in less than $50 \%$ of high-risk patients (excepting increasing nursing observations). The components most frequently unavailable were the ability to provide care in a higher care ward (32.1\%) and assigning the patient to a bed in view of the nurses' station (28.4\%). Failure to comply with available components of the intervention ranged from $27.5 \%$ to $54.3 \%$. The post pilot survey had a response rate of 30/40 (75\%). In Likert scale questions about acceptability, appropriateness, and feasibility of the ASOS-2 intervention, $63 \%$ to $87 \%$ of respondents indicated agreement. Respondents reported barriers related to resources, trial processes, teamwork and communication as reasons for disagreement.

Conclusions: The proposed ASOS-2 Trial appears to be appropriate, acceptable and feasible in Africa. This pilot trial provides support for the proposed ASOS-2 Trial. It emphasises the need for establishing trial site teams which address the needs of all stakeholders during the trial. A concerted effort must be made to help participating hospitals to increase compliance with all the components of the proposed intervention of 'increased postoperative surveillance' during the ASOS-2 Trial.

Keywords: Trial, cluster randomised, Trial, pilot, Implementation science, Mixed methods, Mortality, Surgery 


\section{Introduction}

The African Surgical Outcomes Study (ASOS) ${ }^{1}$ was designed to provide robust surgical outcomes data from Africa, to inform the Commission on Global Surgery. ${ }^{2}$ ASOS showed that surgical patients in Africa were generally young, and of a low surgical risk, yet, when compared to the global average, they were twice as likely to die following surgery. ${ }^{1}$ It is possible that the increase in mortality was predominantly secondary to failure to rescue, which is death following complications. ${ }^{1}$ ASOS suggested that limited surgical resources, in terms of personnel and facilities, compromise provision of a safe postoperative environment for surgical patients in Africa.

The limited variation in postoperative morbidity and mortality across the countries in ASOS,' suggests that a continent-wide strategy to provide safer postoperative care may decrease surgical mortality in Africa. With limited resources available for postoperative care, a strategy is needed that focuses care on the patients at greatest risk of severe complications and death. Identifying high-risk patients and instituting increased postoperative surveillance selectively for these patients may decrease failure to rescue, and hence decrease mortality. This is the strategy which has been adopted for the African Surgical OutcomeS-2 (ASOS-2) Trial; a cluster randomised trial to determine whether increased postoperative surveillance of adult African surgical patients reduces postoperative mortality. ${ }^{3}$

The objectives of the ASOS-2 Pilot Trial were: i) to evaluate the adequacy of data produced by the sampling and data collection strategies of the ASOS-2 Trial, ii) to evaluate the fidelity of implementation of the trial intervention, and iii) to understand the acceptability, appropriateness and feasibility of the intervention and the trial processes.

\section{Methods}

This pilot study is presented in accordance with the CONSORT recommendations for randomised pilot and feasibility trials. ${ }^{4}$

\section{Trial design}

The proposed ASOS-2 Trial is a pragmatic trial. It is an international cluster randomised controlled trial in African countries. Participating surgical sites will be randomised to either the intervention arm of increased postoperative surveillance or the control arm of usual postoperative care. All consecutive adult patients aged 18 years and over admitted to participating sites undergoing elective and non-elective surgery are to be included in the trial. Sites which have been randomised to the intervention arm will need to provide increased postoperative surveillance to those surgical patients with a risk score of $\geq 10$ according to the ASOS Surgical Risk Calculator. The ASOS Surgical Risk Calculator was developed from the first ASOS data and recently published elsewhere. ${ }^{5}$ The primary outcome of the ASOS-2 Trial is inhospital mortality, censored at 30 days.
The ASOS-2 Pilot Trial was a mixed-methods (quantitativequalitative) implementation study evaluating the intervention arm of the proposed ASOS-2 Trial. For the pilot trial the intervention protocol was implemented at all sites for a sevenday period at which time data collection was stopped. Data was collected by means of a case report form (CRF) and an electronic post-pilot survey (Appendices 1 and 2). The CRF documented the necessary data to measure: i) completeness of trial data and ii) fidelity of implementation of the intervention. The survey was used to collect additional data on the implementation outcomes (fidelity, acceptability, appropriateness and feasibility). The survey contained two sections: i) the study intervention (increased postoperative surveillance guided by the risk calculator), and ii) the trial processes. The types of questions used were a combination of Likert scale and open questions. The ASOS-2 Pilot Trial was not registered on a trial registry.

\section{Participants}

Eligible participants included all consecutive adult patients aged 18 years and over admitted to participating sites undergoing elective and non-elective surgery. Pilot sites were selected based on readiness to participate. Only sites with full local ethical approval could participate in the pilot. The initial ethics approval was from the Human Research and Ethics Committee of the University of Cape Town (HREC 081/2018). The trial has a waiver of individual consent, and operated on a broadcast consent model, where participating sites broadcast their involvement in the trial by means of publicly visible posters.

The post-pilot survey was conducted on the REDCap platform ${ }^{6}$ and distributed via email to named investigators one week after the pilot project. Survey responses were anonymous.

\section{Interventions}

All eligible surgical patients were screened with the ASOS Surgical Risk Calculator. ${ }^{5}$ Patients scoring 10 or more points, were considered high-risk, as they have a predicted incidence of severe complications and death above the average for the ASOS cohort. ${ }^{5}$ The protocol required that these patients receive increased postoperative surveillance which included the following components: i) admission to a higher care ward than had been planned prior to risk stratification, ii) an increase in the frequency of postoperative nursing observations, iii) ensuring that the patient is placed in view of the nursing station, and not in a remote location in the ward, or iv) allowing family members to stay with the patient in the ward. The care givers were encouraged to provide as many of the components of the intervention, for as long as possible to the high-risk patients. A bedside clinical guidance poster was provided for all high-risk patients with information on the leading causes of postoperative mortality in African surgical patients as documented in ASOS; these were surgical site infections, bloodstream infection and acute respiratory distress syndrome, pneumonia, acute kidney injury, postoperative bleeding, and cardiac arrest. ${ }^{1}$ A WhatsApp messaging programme was integrated into the REDCap data 
collection tool. The WhatsApp programme provided automated responsive data collection reminders to support clinician registration and to improve data integrity and completeness.

\section{Outcomes}

The effectiveness outcomes (mortality and severe complications) of the ASOS-2 Trial were not captured during the ASOS-2 Pilot Trial, as data collection was stopped at seven days and the pilot was not powered to measure these outcomes. Based on our previous ASOS experience, we are confident that we can capture these data during the full trial. ${ }^{1}$

The implementation outcomes of the pilot were: i) percentage completeness of data produced by the sampling and data collection strategies, ii) fidelity of implementation of the trial intervention, and iii) acceptability, appropriateness and feasibility of the intervention and the trial processes.

Fidelity was defined as individual patient level exposure to increased surveillance, measured quantitatively with the CRF. It assessed the number of surveillance methods a patient was exposed to, the duration of days for which each of these were implemented, and the perceived ease or difficulty of implementation. Acceptability, appropriateness and feasibility were measured qualitatively and semi-quantitatively (by Likert scale) at the individual investigator level by means of a post-pilot investigator survey. Acceptability was defined as stakeholder comfort with the content and complexity of the intervention they are asked to implement. Appropriateness was defined as stakeholder belief about necessity and a goodness of fit of the intervention for their hospital. Feasibility was defined as stakeholder opinion regarding utility and sustainability of the intervention at their hospital. No changes were made to the pilot trial assessments or measurements after the pilot trial commenced.

\section{Theoretical framework}

The post-pilot survey was built around the implementation outcomes proposed by Proctor ${ }^{7}$ and operationalised using selected questions from the Consolidated Framework for Implementation Research (CFIR) interview guide tool. ${ }^{8}$ Essentially the outcome of the ASOS-2 trial depends not only on whether increased postoperative surveillance truly decreases postoperative mortality and morbidity, but also the degree to which increased postoperative surveillance can be implemented in a real-world setting. The CFIR framework addresses elements of the intervention, the context and the process as drivers of fidelity of implementation. Although the questions in the postpilot survey were modelled around an established framework, they have not been validated in this setting, and for this reason the survey employed a mixed-methods approach.

The pilot trial was conducted to inform changes to the proposed protocol to ensure the success of the ASOS-2 Trial, as such there were no prespecified criteria used to judge whether to proceed with a future definitive trial.

\section{Sample size}

There was no proposed sample size for the pilot trial. The sample represents the maximum number of trial centres that were willing to participate and had full ethical approval at the date determined for the pilot trial. There were no stopping rules for the pilot trial, as the trial was to run for one week, and there would be insufficient time to determine any indication for stopping. The survey sampling strategy aimed to avoid duplicate responses by sending a link to the electronic survey to individual named investigators.

All pilot sites were in the intervention arm, hence there was no randomisation, or need for allocation concealment. There was no blinding in the pilot trial.

\section{Implementation}

All patients who had surgery from Monday to Friday of the recruitment week, were risk stratified using the ASOS Surgical Risk Calculator at the time of surgery by the anaesthetist. ${ }^{5}$ Any patient with a score of 10 or more, was considered high-risk, and would require increased postoperative surveillance. The pilot trial ran for one week from 7 am on the Monday, to 6.59 am on the following Monday. Both the intervention and the patient follow-up finished at the end of the pilot week.

\section{Statistical analysis}

Quantitative analyses. When appropriate, categorical variables were compared using Fisher's exact test. Likert scale responses were treated as ordinal data and summarised using proportions ( $\mathrm{n} / \mathrm{N}$ [\%]). Continuous variables were tested and confirmed for normality, summarised using mean and standard deviation, and compared using unpaired t-tests, as all data was normally distributed.

Qualitative analyses. Free text responses to open questions were analysed through an iterative process by two investigators to identify common codes and code categories. LDT and BMB independently coded the data with a constructivist approach; no codes or code categories were specified up front. Following independent coding of all responses, LDT and BMB agreed on a final coding method and worked together to collapse codes to the minimum number of codes that remained representative of all responses. Finally, the data structure was extracted to a coding matrix and narrative summaries prepared around the themes in the matrix.

Statistical analyses were performed using the Statistical Package for the Social Sciences (SPSS) version 24 (SPSS Inc., Chicago, IL, USA) and R statistical software package version 3.4 (R Foundation for Statistical Computing, Austria). Qualitative data analysis was done in RQDA: R-based Qualitative Data Analysis. R package version 0.3-1 (2018). http://rqda.r-forge.r-project.org/ 


\section{Results}

\section{Participants}

803 patients were recruited in the ASOS-2 Pilot Trial, from 16 hospitals in eight countries; Benin (5\%), Democratic Republic of the Congo (<1\%), Kenya (3\%), Mali (4\%), Mauritius (9\%), Niger (6\%), Nigeria (4\%), and South Africa (68\%). These hospitals included one district hospital (contributing 14\% of participants), six secondary hospitals (contributing $20 \%$ of participants), and nine tertiary hospitals (contributing $66 \%$ of participants). Seven hospitals provided eligible patient screening data, of which six entered data on $98.5 \%$ of eligible patients into the database. The seventh hospital provided patient data on 146/195 (74.9\%) of all patients eligible for the pilot trial.

The patient recruitment in the ASOS-2 Pilot Trial is shown in Figure 1. Less than $2 \%$ of the patients were not risk stratified using the ASOS Surgical Risk Calculator. The proportion of agreement with patient risk stratification was $96.7 \%$ with the ASOS Surgical Risk Calculator score ( $\mathrm{K}=0.88)$. 125/772 (16.2\%) were risk stratified as high-risk patients based on an ASOS Surgical Risk Calculator score of 10 or more. The mean (standard deviation) ASOS Surgical Risk Calculator score was 5 (3) for the not high-risk patients, and 13 (3) for the high-risk patients.

\section{Recruitment}

Each pilot site selected a single recruitment week between September and November 2018.

\section{Patient characteristics}

The patients' characteristics are shown in Table 1. Most of the patients had a good physical status classification, with 649/772 (84.1\%) being American Society of Anesthesiologists (ASA) category 1 or 2 . More than half of the surgical procedures were urgent or emergent, and over $2 / 3$ were classified as being of intermediate or major severity. Over a $1 / 3$ of all operations were obstetric procedures.

\section{The fidelity of the 'increased postoperative surveillance' intervention}

The proportion of patients who received increased postoperative surveillance is shown in Table 2. Two-thirds of patients classified as high-risk received increased postoperative surveillance. Of the four components comprising increased postoperative surveillance, only increased nursing observations were used in more than $50 \%$ of patients. The median duration of increased postoperative surveillance was two days for all components, with the exception of utilisation of a higher care ward which was 0 days. The postoperative surveillance bedside guide was placed at the patient's bedside in $48 \%$ of cases.

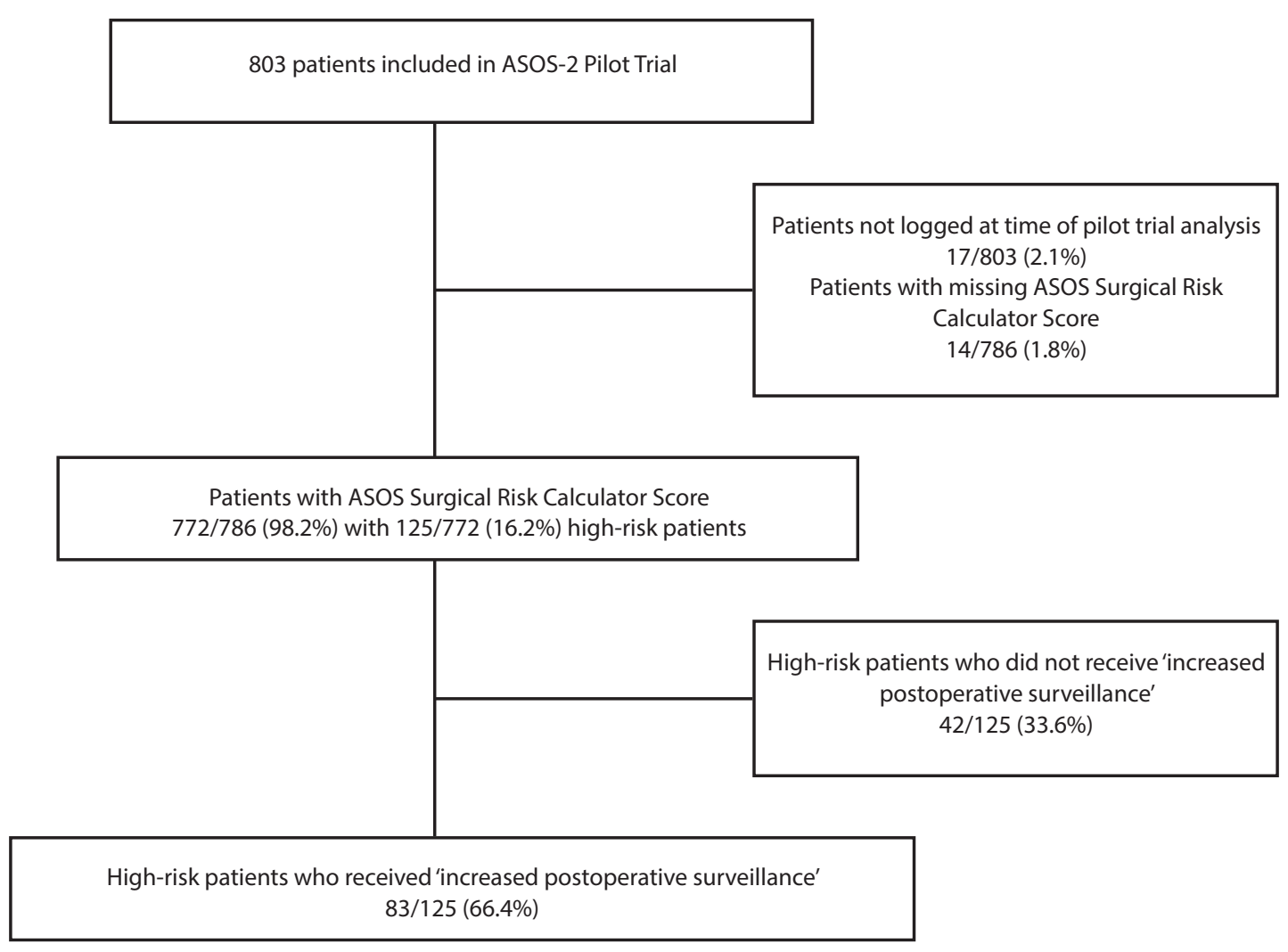

Figure 1. African Surgical OutcomeS-2 (ASOS-2) Pilot Trial flow diagram of patient recruitment 
Table 1. Description of patient cohort and associated 'increased postoperative surveillance'

\begin{tabular}{|c|c|c|c|c|}
\hline & All patients $(n=786)$ & $\begin{array}{l}\text { Patients with 'increased } \\
\text { postoperative surveillance' } \\
(n=125)\end{array}$ & $\begin{array}{l}\text { Patients without 'increased } \\
\text { postoperative surveillance' } \\
(n=647)\end{array}$ & P value \\
\hline Age (years) & $39.0(16.4)$ & $46.3(18.7)$ & $38.6(16.2)$ & $<0.001$ \\
\hline Female & $508 / 765(66.4 \%)$ & 45/121 (37.2\%) & 463/644 (71.9\%) & \\
\hline Male & $257 / 765$ (33.6\%) & $76 / 121(62.8 \%)$ & $181 / 644(28.1 \%)$ & $<0.001$ \\
\hline \multicolumn{5}{|l|}{ ASA category } \\
\hline 1 & 289/772 (37.4\%) & $23 / 125(18.4 \%)$ & $266 / 647$ (41.1\%) & $<0.001$ \\
\hline 2 & $360 / 772(46.6 \%)$ & $37 / 125$ (29.6\%) & $323 / 647$ (49.9\%) & \\
\hline 3 & $116 / 772(15.0 \%)$ & $58 / 125(46.4 \%)$ & $58 / 647$ (9.0\%) & \\
\hline 4 and 5 & $7 / 772(0.1 \%)$ & $7 / 125(5.5 \%)$ & $0 / 647(0.0 \%)$ & \\
\hline \multicolumn{5}{|l|}{ Grade of surgery } \\
\hline Minor & $184 / 772(23.8 \%)$ & $7 / 125(5.6 \%)$ & $177 / 647$ (27.4\%) & $<0.001$ \\
\hline Intermediate & $468 / 772(60.6 \%)$ & $66 / 125(52.8 \%)$ & $402 / 647(62.1 \%)$ & \\
\hline Major & $120 / 772(15.5 \%)$ & $52 / 125(41.6 \%)$ & $68 / 647$ (10.5\%) & \\
\hline \multicolumn{5}{|l|}{ Urgency of surgery } \\
\hline Elective & $356 / 772(46.1 \%)$ & $29 / 125$ (23.2\%) & $327 / 647$ (50.5\%) & $<0.001$ \\
\hline Urgent & $230 / 772(29.8 \%)$ & $57 / 125(45.6 \%)$ & $173 / 647$ (26.7\%) & \\
\hline Emergency & $186 / 772(24.1 \%)$ & $39 / 125(31.2 \%)$ & $147 / 647$ (22.7\%) & \\
\hline \multicolumn{5}{|l|}{ Surgical speciality } \\
\hline Orthopaedic & $138 / 772(17.9 \%)$ & $15 / 125(12.0 \%)$ & $123 / 647$ (19.0\%) & 0.073 \\
\hline Plastics or Breast & $28 / 772(3.6 \%)$ & $3 / 125$ (2.4\%) & $25 / 647$ (3.9\%) & 0.423 \\
\hline Obstetrics & $273 / 772(35.4 \%)$ & $3 / 125$ (2.4\%) & $270 / 647(41.7 \%)$ & $<0.001$ \\
\hline Gynaecology & $74 / 772(9.6 \%)$ & $1 / 125(0.8 \%)$ & $73 / 647(11.3 \%)$ & $<0.001$ \\
\hline Gastro-intestinal or Hepatobiliary & $102 / 772(13.2 \%)$ & $56 / 125(44.8 \%)$ & $46 / 647(7.1 \%)$ & $<0.001$ \\
\hline Urology & $52 / 772(6.7 \%)$ & $8 / 125(6.4 \%)$ & $44 / 647$ (6.8\%) & 1.0 \\
\hline Cardiothoracic/Vascular & $20 / 772(2.6 \%)$ & $14 / 125(11.2 \%)$ & 6/647 (0.9\%) & $<0.001$ \\
\hline Nar, nose and throat & $17 / 772(2.2 \%)$ & $3 / 125$ (2.4\%) & $14 / 647(2.2 \%)$ & 0.869 \\
\hline Neurosurgery & $17 / 772(2.2 \%)$ & $14 / 125(11.2 \%)$ & $3 / 647(0.5 \%)$ & $<0.001$ \\
\hline Other & $51 / 772(6.6 \%)$ & $8 / 125(6.4 \%)$ & $43 / 647(6.6 \%)$ & 1.0 \\
\hline \multicolumn{5}{|l|}{ Indication for surgery } \\
\hline Non-communicable disease & $328 / 772(42.5 \%)$ & $52 / 125(41.6 \%)$ & $276 / 647$ (42.7\%) & 0.844 \\
\hline Infection & $83 / 772(10.8 \%)$ & $43 / 125(34.4 \%)$ & $40 / 647(6.2 \%)$ & $<0.001$ \\
\hline Trauma & 105/772 (13.6\%) & $29 / 125(23.2 \%)$ & $76 / 647(11.7 \%)$ & 0.001 \\
\hline Caesarean section & $256 / 772(33.2 \%)$ & $1 / 125(0.8 \%)$ & $255 / 647$ (39.4\%) & $<0.001$ \\
\hline \multicolumn{5}{|l|}{ Preoperative comorbidity } \\
\hline Hypertension & $157 / 763(20.6 \%)$ & $44 / 121(36.4 \%)$ & $113 / 642(17.6 \%)$ & $<0.001$ \\
\hline COPD/Asthma & 69/761 (9.1\%) & 16/121 (13.2\%) & $53 / 640(8.3 \%)$ & 0.086 \\
\hline HIV positive/AIDS & $84 / 761$ (11.0\%) & $5 / 121(4.1 \%)$ & $79 / 640$ (12.3\%) & 0.007 \\
\hline
\end{tabular}

Data are mean (SD) or $\mathrm{n}$ (proportion). Odds ratios (unadjusted) were constructed for in-hospital severe complications and death with univariable binary logistic regression analysis. The denominator for each group is shown. ASA=American Society of Anesthesiologists. GIT= gastrointestinal. $\mathrm{COPD}=$ chronic obstructive pulmonary disease. $\mathrm{HIV}=$ human immunodeficiency virus. AIDS=acquired immunodeficiency syndrome.

The ease and difficulty of providing the individual components of increased postoperative surveillance are shown in Table 3. The components of increased postoperative surveillance most frequently unavailable were the ability to provide care in a higher care ward (32\%) and assigning the patient to a bed in view of the nurses'station (28\%). When provided, the easiest components to implement were assigning the patient to a bed in view of the nurses' station (39\%) or having the family with the patient in the ward (39\%). A failure to comply with the available components of the intervention (not done) ranged from $28 \%$ to $54 \%$.

\section{The post ASOS-2 Pilot Trial survey}

The post-pilot survey had a response rate of 30/40 (75\%). Of the respondents, 15 were anaesthesia providers, 14 were surgery providers, and one was a nurse. Likert responses to questions 
Table 2. Description of the 'increased postoperative surveillance' provided to 'high-risk' patients

\begin{tabular}{|c|c|c|}
\hline & \multicolumn{2}{|c|}{$\mathrm{n} / \mathrm{N}(\%, 95 \% \mathrm{CI})$} \\
\hline Proportion of high-risk patients in the sample & \multicolumn{2}{|c|}{$125 / 772(16.2 \%, 13.6-18.8)$} \\
\hline Proportion of high-risk patients that received 'increased postoperative surveillance' & \multicolumn{2}{|c|}{$83 / 125(66.4 \%, 58.1-74.7)$} \\
\hline Intervention & Proportion [n/N(\%)] & Days (median, IQR) \\
\hline Higher care ward & $38 / 125(30.4 \%)$ & 0 days $(0-2)$ \\
\hline Increased nursing observations & $75 / 125(60.0 \%)$ & 2 days $(1-4)$ \\
\hline Assigned a bed in view of nurses' station & $51 / 125(40.8 \%)$ & 2 days $(0-3)$ \\
\hline Family with patient in ward & $42 / 125(33.6 \%)$ & 2 days $(0-4)$ \\
\hline 'Postoperative surveillance bedside guide' at the patient's bedside? & $60 / 125(48.0 \%)$ & 2 days $(0-5)$ \\
\hline
\end{tabular}

$\mathrm{Cl}$ confidence interval; IQR interquartile range

about acceptability, appropriateness, fidelity, and feasibility of the intervention is shown in Table 4, the trial processes in Table 5, and qualitative responses in Supplementary Table 1.

In response to Likert scale questions about acceptability of the various components of the intervention, $63 \%$ to $84 \%$ of respondents rated the components acceptable, except for family presence at the bedside, which only $37 \%$ of respondents rated as acceptable. In the qualitative feedback, most respondents (17/25 [68\%]) reported that the intervention is acceptable and will improve quality of care. Reasons for not accepting the intervention were related to scarce personnel and physical resources, obstructive hospital policies and practices, a misunderstanding of the risk calculator, and inadequate communication with stakeholders.

In response to Likert scale questions, $70 \%$ to $87 \%$ of respondents rated the intervention as appropriate. Only 15 (50\%) of respondents answered the open question about relative advantage of the intervention. Their responses were balanced (seven positive versus eight negative). Respondents typically reported personnel constraints and need for education of frontline staff as barriers to implementation. Some of the responses suggested either the question or the intervention was misunderstood. In both instances improved communication with stakeholders was indicated.

In response to Likert scale questions, $69 \%$ to $79 \%$ of respondents rated the ASOS-2 intervention as feasible. 20/30 [67\%] of respondents answered the open question about resource readiness. They listed bed capacity, structural limitations (ward layout), personnel shortage, a need for monitoring equipment and financial constraints as barriers to implementation. Respondents also listed barriers not related to resources (hospital policies and nursing management approval).

In response to the Likert scale question, $73 \%$ of the respondents believed that they truly provided 'increased postoperative surveillance.' The fidelity as measured by the CRF showed that $83 / 125(66 \%)$ of high-risk patients received some form of increased postoperative surveillance.

Responses to the Likert scale questions on trial processes included 13 respondents who received WhatsApp messages during the pilot. Their responses varied. $85 \%$ found the messages useful and would like to receive the message support during the full trial. However, in response to a question about goodness of fit, only $4 / 13$ (31\%) of respondents thought the WhatsApp messages were a good fit. Seven respondents answered the open question about the WhatsApp messages, their responses address the distribution of WhatsApp communication, the nature of messages and the potential burden of receiving too many messages.

In response to Likert questions about stakeholder involvement and leadership, $64 \%$ to $76 \%$ of respondents indicated agreement with the trial processes. The qualitative responses suggested that the full range of stakeholders, from family and frontline staff, to heads of departments (HODs) and hospital management need engagement in the implementation process.

The respondents generally agreed that the CRF was acceptable. Respondents were less decisive about the REDCap data capturing system, 5/11 (45\%) agreed it was 'straightforward', while 4/11 (36\%) remained undecided.

$80 \%$ of the respondents believe that they have the capacity to do ASOS network projects annually.

The qualitative questions were structured to elicit information on specific aspects of implementation, however, many of the responses overlapped between the questions. The central themes that were identified in the responses are presented in the coding matrix (Supplemental Table 1). These themes can be summarised as a need for improved communication with stakeholders, development of site investigator teams, managing the concern of limited resource capacity, and streamlining the trial process.

No adverse events related to the trial were reported.

\section{Discussion}

\section{Statement of principal findings}

The ASOS-2 Pilot Trial had three objectives. With respect to the first objective, the pilot trial suggested that the data produced by the sampling and data collection strategies was good with almost $98 \%$ complete data collection for the pilot. The data was sufficiently pragmatic to describe the cohort, allow risk stratification, and characterise the intervention adequately. The 
Table 3. The ease and difficulty of providing 'increased postoperative surveillance'

\begin{tabular}{|c|c|c|c|c|}
\hline Intervention & Intervention unavailable & $\begin{array}{l}\text { Intervention not } \\
\text { done }\end{array}$ & $\begin{array}{l}\text { Intervention } \\
\text { provided but difficult }\end{array}$ & $\begin{array}{l}\text { Intervention } \\
\text { provided and easy }\end{array}$ \\
\hline Higher care ward & $36 / 112(32.1)$ & $40 / 112(35.7)$ & $23 / 112(20.5)$ & $13 / 112(11.6)$ \\
\hline Increased nursing observations* & $20 / 135(14.8)$ & $43 / 135$ (31.8) & $29 / 135(21.5)$ & $43 / 135$ (31.9) \\
\hline $\begin{array}{l}\text { Assigned a bed in view of nurses' } \\
\text { station }\end{array}$ & $31 / 109(28.4)$ & $30 / 109(27.5)$ & $6 / 109(5.5)$ & $42 / 109(38.5)$ \\
\hline Family with patient in ward & $3 / 94(3.2)$ & $51 / 94(54.3)$ & $3 / 94(3.2)$ & $37 / 94(39.4)$ \\
\hline $\begin{array}{l}\text { 'Postoperative surveillance bedside } \\
\text { guide' at the patient's bedside? }\end{array}$ & $3 / 110(2.7)$ & $51 / 110(46.4)$ & $11 / 110(10.0)$ & $45 / 110$ (40.9) \\
\hline
\end{tabular}

*Denominator $>125$ due to high-risk patients both receiving and not receiving the intervention on different days

cohort description supports data adequacy since the patients and the procedures correspond with those recorded in the first ASOS study.

The second objective was to evaluate the fidelity of implementation of the trial intervention. The pilot trial suggests that the ASOS Surgical Risk Calculator ${ }^{5}$ is easy to use to identify the high-risk patient. The individual components of the intervention were implemented in less than $50 \%$ of high-risk patients (with the exception of increasing nursing observations) (Table 2). The compliance with the intervention may therefore be considered poor, especially as the individual components could have been increased by between $28 \%$ and $54 \%$ in the current cohort, and most respondents considered the components of the intervention 'easy' to implement with the exception of placement in a higher care ward (Table 3). An important observation is that despite our assessment of the compliance with the intervention being poor, the respondents believed that they had indeed provided 'increased postoperative surveillance' to the 'high-risk' patients (Table 4).

The third objective was to understand the acceptability, appropriateness and feasibility of the intervention. The pilot suggests that the proposed ASOS-2Trial is acceptable, appropriate and feasible. The majority of the qualitative responses were very supportive of the proposed intervention (Supplementary Table 1). The only component of the intervention which the median respondent considered unacceptable was having the patient's family at the bedside. The qualitative responses suggested that this was multifactorial; which included staffing attitudes, hospital policy, security, and ward space. The trial intervention was generally considered acceptable. Involving stakeholders was considered simple by the investigators. However, the hospital which provided data on only $75 \%$ of all eligible patients screened, had particular difficulty establishing a pilot trial hospital team. The qualitative data clearly identifies that the stakeholders in the trial cover the broad range of hospital management, surgeons, anaesthetists, nursing staff, and other frontline ward staff.

The trial processes suggest that the negative score for Caesarean section on the ASOS Surgical Risk Calculator, creates the impression that obstetrics is not considered as a serious risk factor. Occasional disagreement between clinical impression of a patient and the ASOS Surgical Risk Calculator was mentioned. The WhatsApp messaging was found to be useful, although there was no consensus on the appropriate number of messages, or the composition of the WhatsApp hospital site investigator group. Some concerns were raised about the data capturing process, specifically the need to return to the data base multiple times for data capture on the same patient.

\section{Limitations}

The pilot trial has poor representation from district hospitals. Furthermore, the pilot did not assess the main trial outcomes, although we are confident in the ability of the investigators to capture these data, as they are similar to those successfully collected across Africa in ASOS. ${ }^{1}$ It is possible that the duration of the components of the intervention may be under-reported, as the pilot trial stopped on the Monday, which is only the third postoperative day for 'high-risk' patients recruited on the Friday into the trial. Acceptable definitions for data completeness and fidelity were not prespecified. This shortcoming will be addressed in the main trial. The pilot survey respondents are not representative of all the key individuals identified in the survey. The anonymous nature of the survey means that we did not collect data regarding the respondents' country or hospital. Therefore, we cannot distinguish differences in responses at a country or hospital level.

\section{Generalisability}

The pilot trial methods and findings may be generalisable to the definitive trial due to: i) completeness of the data collection, and ii) the consistency in the survey responses regarding acceptability, appropriateness, and feasibility in the survey, despite data from hospitals across eight African countries. Importantly, there was overwhelming support for the appropriateness of the proposed intervention in the qualitative assessment. 


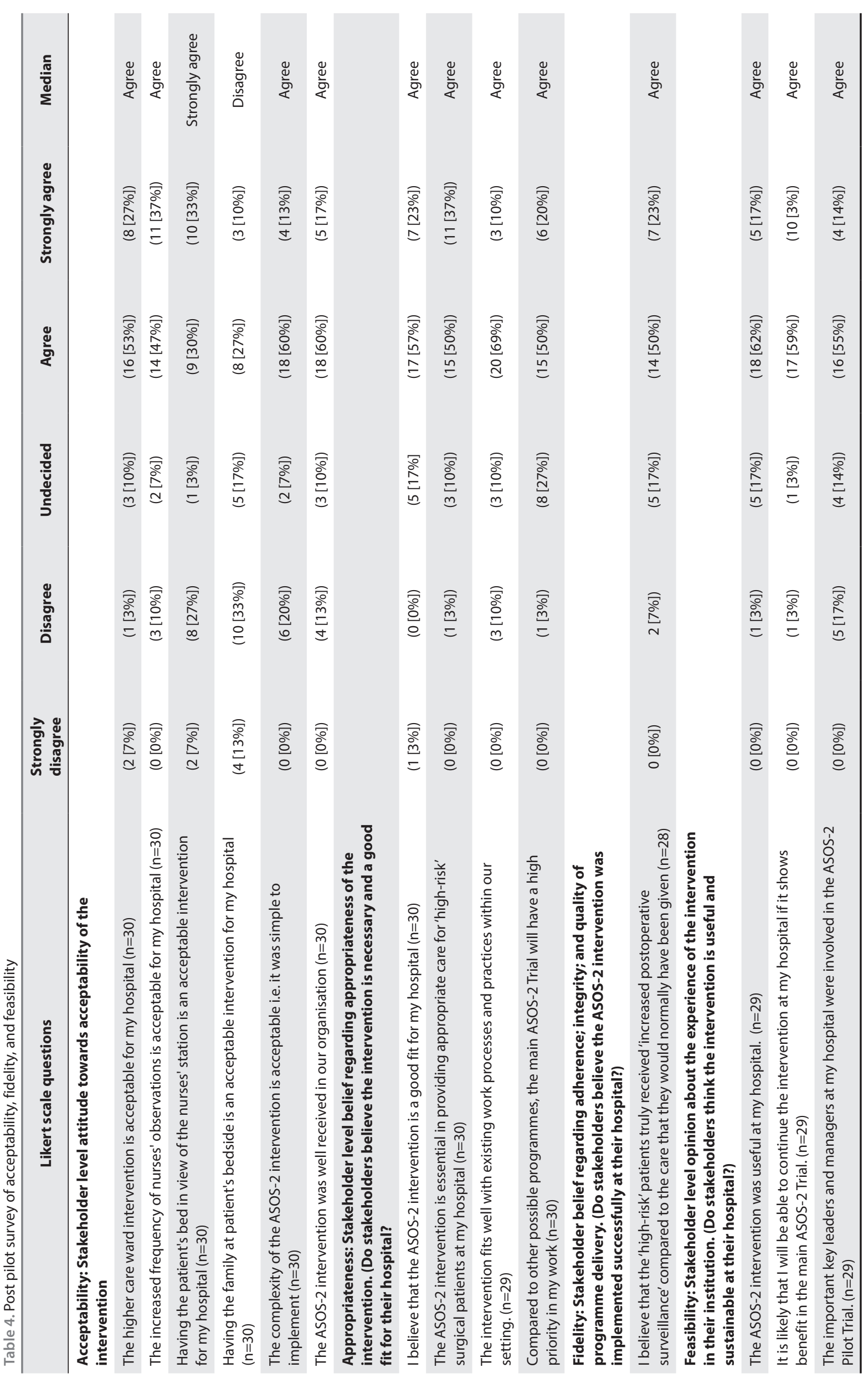




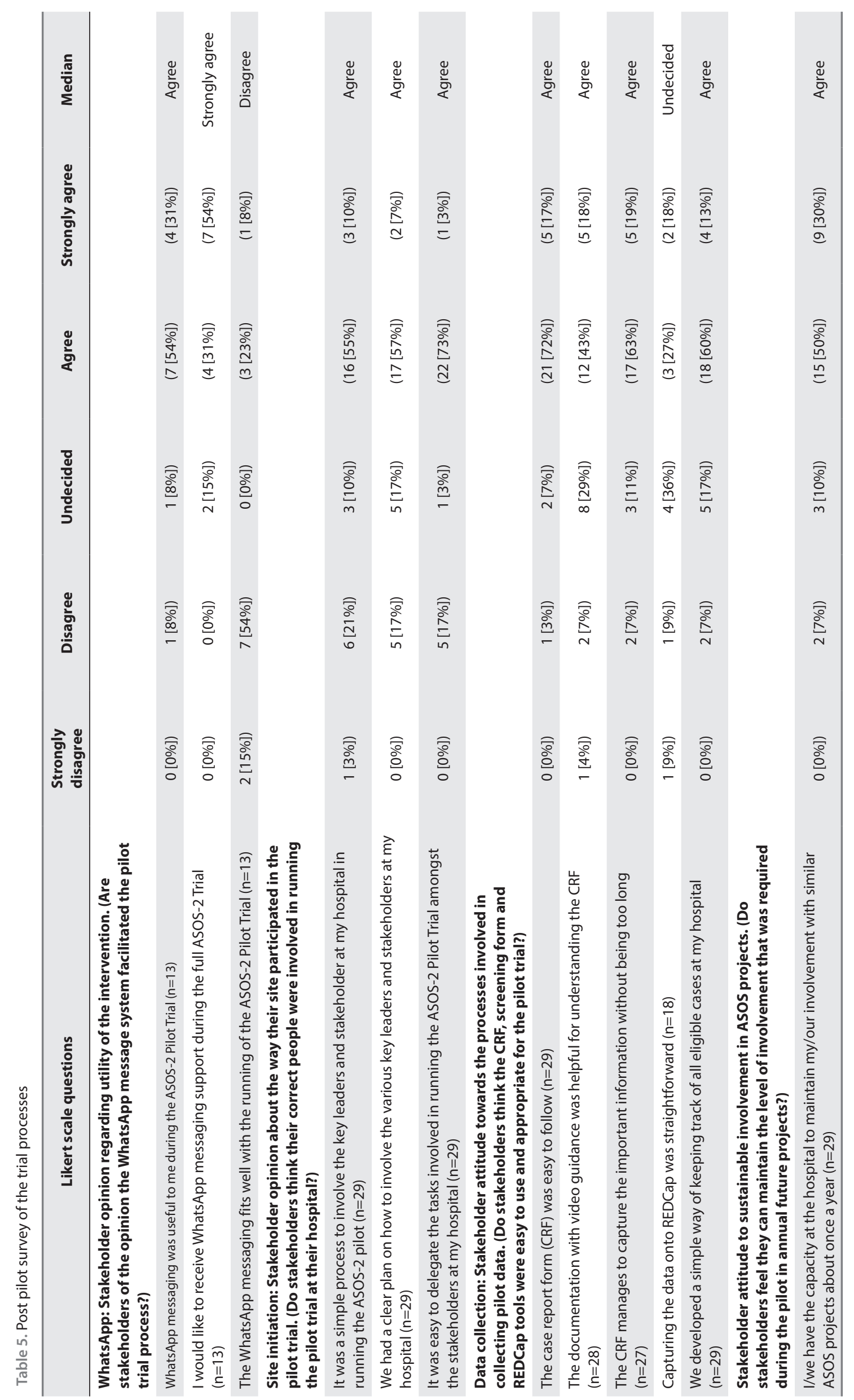




\section{Interpretation}

We believe that the pilot trial was successful, as it has provided valuable information on all three of its objectives. These data have important implications for progression from the pilot to the future definitive trial.

To improve fidelity we must secure: i) a representative local trial team with accepted leadership structure at each hospital, ii) buyin to a shared vision by all key individuals, iii) define adequacy of increased surveillance, iv) improve education and training on implementation of the intervention, and v) identify agreed workarounds for barriers to implementation that are specific to the sites (e.g. address problems with ward layout, bed allocation and family visitation policies). These goals can be achieved by involving a broader range of stakeholders in the local trial team, increasing contact time with site investigators during the buildup to the trial, increasing education during site enrolment and initiation, and providing a roll-in period for the site to test the protocol and establish acceptable workarounds prior to the ASOS-2 Trial.

Although the ASOS Surgical Risk Calculator was simple to use for risk stratification in the pilot trial, it is necessary to educate investigators in the principles related to i) the derivation of the calculator (and hence the individual point scores), ii) the expected outcomes associated with a score above the cut for high-risk in the trial, immaterial of the clinical impression, and iii) the expected number of patients that will require increased surveillance per day.

The WhatsApp groups may need to be individualised according to local needs at each site. Moreover, it would be desirable to simplify the patient data capture portal. We believe this will be possible in the definitive trial, when the questions around 'fidelity' of implementation which were specific to the pilot trial will be removed.

Exposure to the individual components of the proposed intervention was suboptimal. A key focus of education during site initiation will be on ensuring that each component of the intervention is maximally applied during the trial. A concern that needs to be addressed, is the current perception that increased postoperative surveillance was done, even though there was substantial room for improvement in delivering the intervention. The recurring concern about resource constraints is a reality of the setting; it should be clarified that the goal of the intervention is not to increase workload for frontline staff, but rather to redistribute resources to those at higher risk of complication.

\section{Conclusion}

Morbidity and mortality following surgery in Africa is significantly worse than the global average. These poor outcomes appear to be consistent across many African countries, a phenomenon which is possibly driven by 'failure to rescue.' 1 The proposed 'increased postoperative surveillance' intervention for the ASOS-2
Trial appears to be appropriate, acceptable and feasible in Africa. This pilot trial provides substantial support for the proposed trial. It emphasises the need to establish site teams that address the needs of all stakeholders, the need to help stakeholders identify ways to work around site specific barriers to implementation, and finally, the need to pursue increased compliance with all the components of the proposed intervention of 'increased postoperative surveillance'.

\section{Contributors}

All authors were involved in the design and conduct of the study. Data collection and collation was done by the ASOS-2 Pilot Trial investigators. The data analysis was conducted by BMB and LDT. The first draft of the paper was written by BMB. The paper was redrafted by BMB and LDT following critical review by all authors.

\section{Declaration of interest}

Praekelt.org and Dr Charles Copley run services delivering health messages over WhatsApp. RP holds research grants and has given lectures and/or performed consultancy work for Glaxo Smithkline, BBraun, Intersurgical and Edwards Lifesciences, and is a member of the Associate editorial boards of the British Journal of Anaesthesia, British Journal of Surgery and BMJ Quality \& Safety. All other authors declare no conflict of interests.

\section{Funding}

The ASOS-2 Pilot Trial was supported by a grant (OPP\#1161108) from the Bill \& Melinda Gates Foundation.

\section{Acknowledgements}

\section{The ASOS Collaborative Network}

\section{Received: 22 January 2019 Accepted: 24 January 2019}

\section{References}

1. Biccard BM, Madiba TE, Kluyts $\mathrm{HL}$, et al. Perioperative patient outcomes in the African Surgical Outcomes Study: a 7-day prospective observational cohort study. Lancet 2018; 391: 1589-98.

2. Meara JG, Leather AJ, Hagander L, et al. Global Surgery 2030: evidence and solutions for achieving health, welfare, and economic development. Lancet 2015; 386: 569-624.

3. ASOS African Surgical Outcomes Study. Available from www.asos.org.za (accessed 21/01/2019).

4. Eldridge SM, Chan CL, Campbell MJ, et al. CONSORT 2010 statement: extension to randomised pilot and feasibility trials. BMJ 2016; 355: i5239.

5. Kluyts HL, le Manach Y, Munlemvo DM, et al. The ASOS Surgical Risk Calculator: development and validation of a tool for identifying African surgical patients at risk of severe postoperative complications. Br J Anaesth 2018; 121: 1357-63.

6. Harris PA, Taylor R, Thielke R, Payne J, Gonzalez N, Conde JG. Research electronic data capture (REDCap)--a metadata-driven methodology and workflow process for providing translational research informatics support. J Biomed Inform 2009; 42: 377-81.

7. Proctor $\mathrm{E}$, Silmere $\mathrm{H}$, Raghavan $\mathrm{R}$, et al. Outcomes for implementation research: conceptual distinctions, measurement challenges, and research agenda. Administration and Policy in Mental Health and Mental Health Services Research 2011; 38: 65-76.

8. Consolidated Framework for Implementation Research (CFIR) Guide. Available from http://cfirwiki.net/guide/app/index.html\#/ (accessed 21/01/2019 2019). 


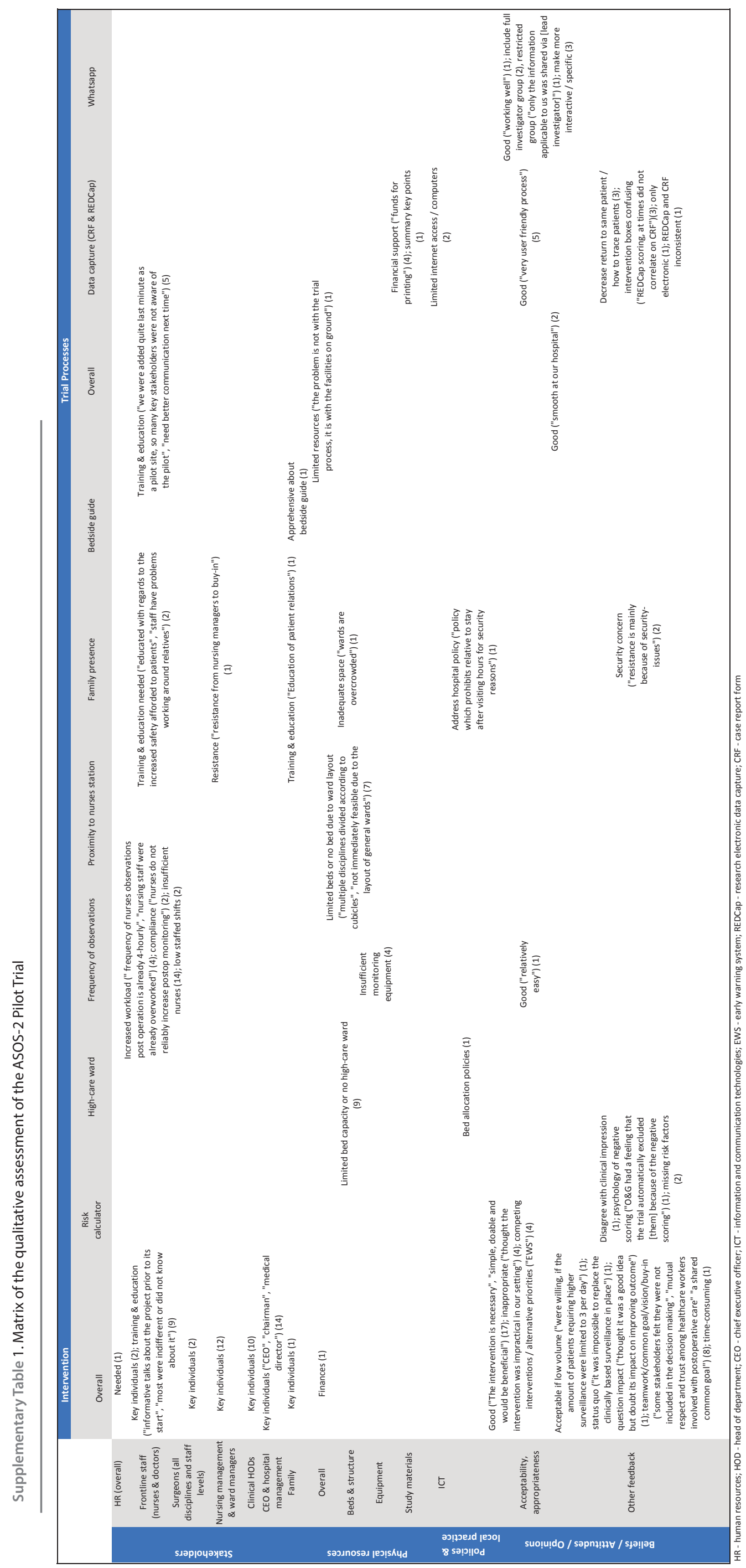


Appendix

Members of the African Surgical OutcomeS-2

(ASOS-2) Pilot Trial

\section{ASOS-2 Pilot Trial Steering Committee:}

B M Biccard, L Du Toit, P Forget, HL Kluyts, R M Pearse.

\section{ASOS-2 Pilot Trial Investigators: Benin. National Leader: $E$} Zoumenou

Centre Hospitalier Universitaire départemental de l'Ouémé et du Plateau (CHUD/OP): Ahounou Ernest.

\section{Democratic Republic of Congo. National Leader: Munlemvo DM}

El Rapha Clinic: T Likongo.

University Hospital of Kinshasa: T Djoho, AKM Kilembe, SHN Nehema.

\section{Kenya. National Leaders: AKN Ndonga, ZWW Ngumi}

Mater Misericordiae Hospital: AKN Ndonga.

\section{Mali. National Leader: Sanogo Zimogo}

CHU du Point G: BD Boubacar, B Moussa, S Zimogo Zié.

Hôpital de Gao: S Souleymane.

\section{Mauritius. National Leader: V Gobin}

Dr AG Jeetoo Hospital: MRA Aboobakar, NF Fokeerah, VMK Kissoon, RR Ramsewak.

Jawaharlall Nehru Hospital: SJ Joomye.

Niger. National Leader: Chaibou M Sani

Centre Hospitalier Regional: FD Djibo.

National hospital de Zinder: $\mathrm{H}$ Adamou, I Amadou Magagi, O Habou

Nigeria. National Leader: Akinyinka O Omigbodun, Simbo DAmanor-Boadu

Aminu Kano Teaching Hospital, Kano: SA Aji, LJC Anyanwu, M Atiku, A Attah, AB Muhammad, RO Oseni, M Salisu-Kabara.

\section{South Africa. National Leader: H-L Kluyts}

Dr George Mukhari Academic Hospital: BJ Baloyi-Mnisi, MZ Koto, ME Mabitsela, T Mabotja, B Mthelebofu, SR Ndlovu.

Nelson Mandela Academic Hospital: B Mrara, AO Usenbo.

New Somerset Hospital: M Nock, AR Reed, H Steinhaus, NJ Vickery

Tygerberg Hospital: RC Pillay.

Worcester hospital: PJ Buckle, PJ Jansen van Vuuren, CM Keen, TA Killingbeck, SJ Kim, N Swanepoel, C van der Westhuizen, HA van Zyl, MM Venter, PJ Viljoen. 


\section{$4 \rightarrow \infty$ \\ African Surgical OutcomeS-2 Trial}

Age $\square \square$ years (<30 points; 0 points/ 30-69 years; 1 point/ $\geq 70$ years; 3 points) Sex $\square \mathrm{M} \square \mathrm{F}$ ASA $\square$ I (0 points) $\square$ II (2 points) $\square$ III (5 points) $\square$ IV (8 points) $\square$ v (8 points) Chronic co-morbid disease (tick all that apply): $\square$ Hypertension $\square$ HIV / AIDS $\square$ Diabetes mellitus $\square$ coPD / Asthma Surgical procedure category (select single most appropriate): $\square$ Gynaecology (minus 1 point) $\square$ obstetrics (minus 1 point) $\square$ Orthopaedic (0 points) $\square$ Ear, nose and throat (3 points) $\square$ Plastics or breast (1 point) $\square$ Urology (2 points) $\square$ Neurosurgery(4 points) $\square$ Gastro-intestinal or Hepato-biliary(3 points) $\square$ Cardiothoracic/ vascular(3 points) $\square$ other(0 points) Indication for surgery:

$\square$ Non-communicable disease (0 points) $\square$ Caesarean section (minus 2 points) $\square$ Trauma (1 point) $\square$ Infection (2 points)

Urgency of surgery: $\quad \square$ Elective (0 points) $\quad \square$ Urgent $\quad$ (3 points) $\square$ Emergency (4 points)

Severity of surgery: $\quad \square$ Minor (0 points) $\quad \square$ Intermediate (2 points) $\square$ Major (4 points)

Start of surgery time $(24 \mathrm{~h}) \&$ date:

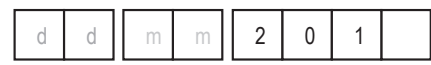

ASOS Surgical Risk Score points per risk factor:

$\square$ Age $+\square$ ASA $+\square$ surgical procedure category $+\square$ Indication for surgery $+\square$ Urgency surgery $+\square$ severity surgery $=\square \square$ points Time that the ASOS Surgical Risk Score was calculated: $\square$ Pre-op $\square$ Intra-op $\square$ Immediately post-op

Predicted ASOS Risk Score: $\square$ Not high-risk patient (<10 points) $\square$ High-risk patient ( $\geq 10$ points)

Postoperative Follow Up
$\square$ Not high-risk patient: (Complete postoperative care given):Higher care ward $\square$ No $\square$ Yes Increased nursing observations $\square$ No $\square$ Yes

Assigned a bed in view of nurses' station $\square$ No $\square$ Yes $\quad$ Family with patient in ward $\square$ No $\square$ Yes

\begin{tabular}{|c|c|c|c|c|c|c|c|}
\hline \multirow{2}{*}{$\begin{array}{l}\square \text { High-risk patient: } \\
\text { (Complete all postop surveillance) }\end{array}$} & \multirow[t]{2}{*}{ Day 0} & \multirow[t]{2}{*}{ Day 1} & \multirow[t]{2}{*}{ Day 2} & \multirow[t]{2}{*}{ Day 3} & \multirow[t]{2}{*}{ Day 4+ } & \multicolumn{2}{|c|}{ Intervention } \\
\hline & & & & & & Any no & Any yes \\
\hline Higher care ward & $\square$ No $\square$ res & $\square$ No $\square$ Yes & $\square$ No $\square$ yes & $\square$ No $\square$ Yes & $\square$ No $\square$ Yes & $\square \square$ & $\square \square$ \\
\hline Increased nursing observations & $\square$ No $\square$ Yes & $\square$ No $\square$ Yes & $\square$ No $\square$ Yes & $\square$ No $\square$ Yes & $\square$ No $\square$ Yes & $\square \square$ & $\square \square$ \\
\hline Assigned a bed in view of nurses' station & $\square$ No $\square$ Yes & $\square$ No $\square$ Yes & $\square$ No $\square$ Yes & $\square$ No $\square$ Yes & $\square$ No $\square$ Yes & $\square \square$ & $\square \square$ \\
\hline Family with patient in ward & $\square$ No $\square$ Yes & $\square$ No $\square$ Yes & $\square$ No $\square$ Yes & $\square$ No $\square$ Yes & $\square$ No $\square$ Yes & $\square \square$ & $\square \square$ \\
\hline $\begin{array}{l}\text { ‘Postoperative surveillance bedside } \\
\text { guide' at the patient's bedside? }\end{array}$ & $\square$ No $\square$ Yes & $\square$ No $\square$ Yes & $\square$ No $\square$ Yes & $\square$ No $\square$ Yes & $\square$ No $\square$ Yes & 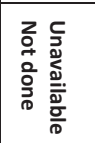 & 罜 \\
\hline
\end{tabular}

Severe complications (tick all that apply): Superficial or deep surgical site, or body cavity infection $\square \mathrm{Y} \square \mathrm{N}$ Postop day $\square \square$

Bloodstream infection or ARDS $\square \mathrm{Y} \square \mathrm{N}$ Postop day $\square \square$ Pneumonia

Urinary tract or AKI $\quad \square \mathrm{Y} \square \mathrm{N}$ Postop day $\square \square \quad$ Postoperative bleed $\quad \square \mathrm{Y} \square \mathrm{N}$ Postop day $\square \square$

Cardiac arrest $\quad \square \mathrm{Y} \square \mathrm{N}$ Postop day $\square \square \quad$ Other severe complication $\quad \square \mathrm{Y} \square \mathrm{N}$ Postop day $\square \square$

Critical care admission to treat postoperative complications: $\square$ No $\square$ Yes Postop day $\square \square \quad$ Days in hospitalter surgery $\square$

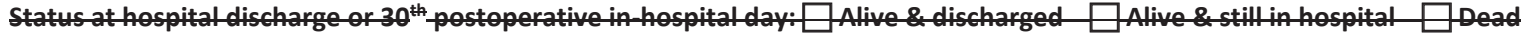

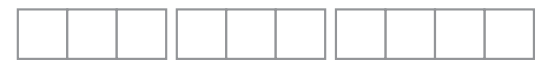

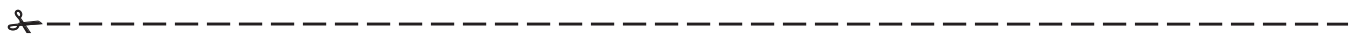

Patient name:

Patient hospital number :
DOB

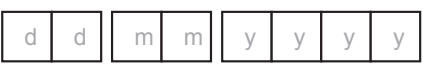

ASOS-2 Pilot Trial CRF 
Definition of 'Indication for surgery': This is the underlying initiating disease/ event which ultimately resulted in the need for surgery. High care ward: A postoperative ward which is dedicated to providing increased postoperative care, when compared to the normal postoperative surgical ward. A high care ward can include an intensive care ward. Increased frequency of nursing observations: Nursing observations which are conducted more frequently, than the normal frequency of observations on the postoperative ward. Patient bed close to nurses' station: The patient is positioned in a bed close to the nursing station to ensure that the nurses can always see the patient from the nursing station. Family members to stay with the patient in the ward: If the family members are asked to stay with the patient on the ward, because of a concern that the patient is at increased risk of death of morbidity in the postoperative period. Number of paces from bed to nurses' station: The number of paces of the shortest distance from the end of the patient's bed to the nurses' station.

Definition of a 'Severe Complication': Results in significant prolongation of hospital stay and/or permanent functional limitation or death. Almost always requires clinical treatment. Surgical site infection (superficial): Infection involving only superficial surgical incision which meets the following criteria: i) Infection occurs within 30 days after surgery and ii) Involves only skin and subcutaneous tissues of the incision and iii) The patient has at least one of the following: a) purulent drainage from the superficial incision, or b) organisms isolated from an aseptically obtained culture of fluid or tissue from the superficial incision and at least one of the following signs or symptoms of infection: pain or tenderness, localized swelling, redness, or heat, or superficial incision is deliberately opened by surgeon and is culture positive or not cultured. A culture-negative finding does not meet this criterion, or c) diagnosis of a incisional surgical site infection by a surgeon or attending physician Surgical site infection (deep): An infection which involves both superficial and deep parts of surgical incision and meets the following criteria: i) Infection occurs within 30 days after surgery if no surgical implant is left in place or one year if an implant is in place and ii) The infection appears to be related to the surgical procedure and involves deep soft tissues of the incision (e.g. fascial and muscle layers) and iii) The patient has at least one of the following: a) purulent drainage from the deep incision but not from the organ/space component of the surgical site, or b) a deep incision spontaneously dehisces or is deliberately opened by a surgeon and is culture-positive or no cultures were taken whilst the patient has at least one of the following signs or symptoms of infection: fever $\left(>38^{\circ} \mathrm{C}\right)$ or localized pain or tenderness. A culture-negative finding does not meet this criterion, or c) an abscess or other evidence of infection involving the deep incision is found on direct examination, during surgery, or by histopathologic or radiologic examination, or d) diagnosis of a deep incisional surgical site infection by a surgeon or attending physician. Surgical site infection (organ/space): An infection which involves any part of the body excluding the fascia or muscle layers and meets the following criteria: i) Infection occurs within 30 days after surgery and ii) The infection appears to be related to the surgical procedure and involves any part of the body, excluding the skin incision, fascia, or muscle layers, that is opened or manipulated during the operative procedure and iii) The patient has at least one of the following: a) purulent drainage from a drain that is placed through a stab wound into the organ/space, b) organisms isolated from an aseptically obtained culture of fluid or tissue in the organ/ space, or c) an abscess or other, or d) evidence of infection involving the organ/space that is found on direct examination, during reoperation, or by histopathologic or radiologic examination, or e) diagnosis of an organ/space surgical site infection by a surgeon or attending physician. Bloodstream infection: An infection which is not related to infection at another site and which meets at least one of the following criteria: i) Patient has a recognised pathogen cultured from blood cultures which is not related to an infection at another site, ii) Patient has at least one of the following signs or symptoms: fever $\left(>38^{\circ} \mathrm{C}\right)$, chills, or hypotension and at least one of the following: a) common skin contaminant cultured from two or more blood cultures drawn on separate occasions, or b) common skin contaminant cultured from at least one blood culture from a patient with an intravascular line, and a physician starts antimicrobial therapy, or c) positive blood antigen test. Acute Respiratory Distress Syndrome (ARDS): Respiratory failure, or new or worsening respiratory symptoms, commencing within one week of surgery; and a chest radiograph or computed tomography scan which demonstrates bilateral opacities not fully explained by effusions, lobar/lung collapse, or nodules; and respiratory failure not fully explained by cardiac failure or fluid overload. Need objective assessment (e.g. echocardiography) to exclude hydrostatic oedema if no risk factor is present. Severity grading: Severe: $\mathrm{PaO} 2 \mathrm{FiO} 2 \leq 100 \mathrm{mmHg}$ with PEEP $\geq 5 \mathrm{cmH} 2 \mathrm{O}$. Guidance: If altitude is higher than $1000 \mathrm{~m}$, a correction factor should be calculated as follows: (PaO2:FiO2 $\mathrm{x}$ [barometric pressure/760 mmHg]). PEEP, positive end-expiratory pressure; CPAP, non-invasive continuous positive airways pressure. Pneumonia: Chest radiographs with new or progressive and persistent infiltrates, or consolidation, or cavitation, and at least one of the following: i) fever ( $\left.>38^{\circ} \mathrm{C}\right)$ with no other recognized cause, or ii) leucopaenia $(<4,000$ white blood cells $/ \mathrm{mm} 3)$ or leucocytosis $(>12,000$ white blood cells $/ \mathrm{mm} 3)$, or iii) for adults $>70$ years old, altered mental status with no other recognised cause; and at least two of the following: a) new onset of purulent sputum or change in character of sputum, or increased respiratory secretions, or increased suctioning requirements, or b) new onset or worsening cough, or dyspnoea, or tachypnoea, or c) rales or bronchial breath sounds, d) worsening gas exchange (hypoxaemia, increased oxygen requirement or increased ventilator demand). Guidance: Two radiographs are required for patients with underlying pulmonary or cardiac disease. The definition may be used to identify ventilator associated pneumonia. Urinary tract infection: An infection associated with at least one of the following signs or symptoms which should be identified within a 24 hour period; fever $\left(>38^{\circ} \mathrm{C}\right)$, urgency, frequency, dysuria, suprapubic tenderness, costovertebral angle pain or tenderness with no other recognised cause, and a positive urine culture of $\geq 105$ colony forming units $/ \mathrm{mL}$ with no more than two species of microorganisms. Acute Kidney Injury (AKI): Serum creatinine Increase of 3.0 times baseline within 7 days or increase in serum creatinine to $\geq 4.0 \mathrm{mg} / \mathrm{dL}$ ( $\geq 354 \mu \mathrm{mol} / \mathrm{L}$ ) with an acute rise of $>0.5 \mathrm{mg} / \mathrm{dL}(>44 \mu \mathrm{mol} / \mathrm{L}$ ) or initiation of renal replacement therapy, or urine output $\leq 0.3 \mathrm{ml} / \mathrm{kg} / \mathrm{h}$ for 24 hours or anuria for 12 hours Guidance: Baseline serum creatinine must be measured before surgery but an estimated value can be used if the patient does not have chronic kidney disease. Postoperative haemorrhage: Blood loss occurring within 72 hours after the end of surgery which would normally result in transfusion of blood. Cardiac arrest: The cessation of cardiac mechanical activity, as confirmed by the absence of signs of circulation. ECG changes may corroborate the incidence of cardiac arrest. Other severe complications: If any of the following complications result in a significant prolongation of hospital stay and/or permanent functional limitation or death, then mark 'Other severe complication' as 'Yes'. Note that they will almost always requires clinical treatment. Critical care admission to treat postoperative complications: Postoperative complications requiring admission to critical care to treat the postoperative complications or provide critical care support necessitated by the severity of the postoperative complications.

Days in hospital after surgery: Total number of days in hospital after surgery. Status at hospital discharge or 30th postoperative in-hospital day: The survival status of the patient at hospital discharge, or at the 30 in-hospital day (if the patient had not yet been discharged following surgery). The study is censored at the 30th in hospital postoperative day.

ASOS-2 unique patient ID

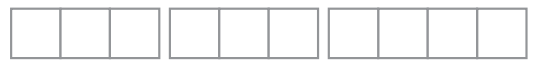

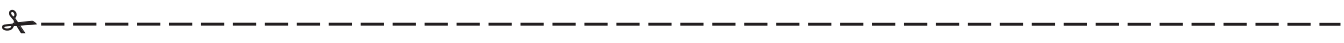

Patient name:

DOB

Patient hospital number :

ASOS-2 Pilot Trial CRF 


\section{ASES-2 \\ African Surgical OutcomeS-2 Trial}

\section{Guidance for use of paper case record form (CRF)}

\section{Remove this page before use in data collection}

1. This CRF is provided in a format which can be edited.

2. Baseline data will often be readily available to anaesthetists during surgery whilst follow-up data on complications may be most easily collected by surgeons.

3. Investigators should write the patient name and date of birth on the CRF. When you enter the data on the internet based CRF you will receive an ASOS-2 patient ID. Please write this on the paper CRF as well in case we need to contact you to check your data.

4. Please take care to enter the date clearly and correctly. Mistakes are common data describing time and date.

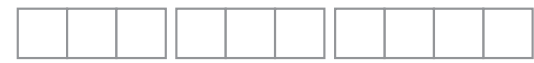

\&- - - - - - - - - - - - - - - - - - - - - - - - - - - - - -

Patient name:

Patient hospital number :
DOB
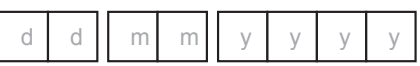

ASOS-2 Pilot Trial CRF 
Appendix 2. An implementation survey for the ASOS-2 pilot trial

Dear ASOS-2 Pilot Trial Investigators

\section{ASOS-2 Pilot Trial Survey}

Informed consent

Dear Colleagues

1. Purpose of survey: To understand your experience of the ASOS-2 Pilot Trial, in order to help us improve the protocol for the main ASOS-2 Trial.

2. Why were you chosen to participate? You have been chosen to participate, as you were an investigator in the ASOS-2 Pilot Trial.

3. Length of participation: This is a simple survey which should take about 15 minutes to complete.

4. Is your identity and information safe? Your personal information will be kept confidential and identity will be kept anonymous. We will be using codes and the only people who will be aware of these codes are the lead investigator (Bruce Biccard) and the REDCap Administrator (Dawid van Straaten).

5. Can I change my mind and withdraw from the survey? Participation in the survey is voluntary. By participating in this survey, you are consenting to participate. Should you wish to withdraw from the survey, you are welcome to do so with no consequences.

6. Feedback: We will provide feedback on the survey to all participants.

7. If I have any queries or problems, who can I get in touch with?

Contact Details for questions relating to the survey:

Professor Bruce Biccard

Department of Anaesthesia and Perioperative Medicine

D23 Groote Schuur Hospital

Faculty of Health Sciences

University of Cape Town

Email: bruce.biccard@uct.ac.za

\section{The survey}

The survey takes the form of two sections; i) The first section contains questions that relate specifically to the ASOS-2 Pilot Trial intervention i.e. the actual act of providing 'increasing postoperative surveillance', and ii) The second section includes questions on the trial processes e.g. getting ethics approval, completing the CRF, working with REDCap etc.

\section{SECTION A: Providing 'increasing postoperative surveillance'}

\section{Definitions}

- "Stakeholders"'"' include: Nurses, clinicians and hospital management

- "Intervention": The action of providing 'increased postoperative surveillance.' The "content" of the intervention are the four options for intervention, i.e. i) higher care ward, ii) increased frequency of nurses' observations, iii) the patient's bed in view of the nurses' station and iv) having the family at patient's bedside.

Please see Table 1

Likert Scale: 1. Strongly disagree, 2. Disagree, 3. Neutral, 4. Agree, 5. Strongly agree

\section{SECTION B: The ASOS-2 Trial processes}

Please see Table 2.

Added questions;

1. I received too many WhatsApp reminders during the ASOS-2 Pilot Trial.

2. I received too many e-mails during the ASOS-2 Pilot Trial.

1. Proctor $E$, Silmere $H$, Raghavan $R$, et al. Outcomes for implementation research conceptual distinctions, measurement challenges, and research agenda. Administration and Policy in Mental Health and Mental Health Services Research 2011; 38: 65-76. 


\begin{tabular}{|c|c|c|}
\hline Conceptual definitions & Operational definitions & Variable definitions \\
\hline \multicolumn{3}{|l|}{ Acceptability } \\
\hline $\begin{array}{l}\text { Stakeholder level attitude towards } \\
\text { acceptability of the intervention }\end{array}$ & $\begin{array}{l}\text { Are stakeholders comfortable with } \\
\text { the content and complexity of } \\
\text { the intervention they are asked to } \\
\text { implement? }\end{array}$ & $\begin{array}{l}\text { 1. [Ordinal] The four components (i.e. higher care ward, increased postop } \\
\text { surveillance etc.) of the ASOS-2 intervention are acceptable for my } \\
\text { hospital. 5-point Likert scale. } \\
\text { 2. [Ordinal] The complexity of the ASOS-2 intervention is acceptable } \\
\text { i.e. it was simple to implement). 5-point Likert scale (CFIR* Intervention } \\
\text { characteristic - complexity) } \\
\text { 3. [Ordinal] The ASOS-2 intervention was well received in our } \\
\text { organization. 5-point Likert scale (CFIR* Inner setting-climate) } \\
\text { 4. [Qualitative] What did the stakeholders at your hospital think of the } \\
\text { intervention? (CFIR* Intervention characteristic-strength of evidence) }\end{array}$ \\
\hline \multicolumn{3}{|l|}{ Appropriateness } \\
\hline $\begin{array}{l}\text { Stakeholder level belief } \\
\text { regarding appropriateness of the } \\
\text { intervention }\end{array}$ & $\begin{array}{l}\text { Do stakeholders believe the } \\
\text { intervention is necessary and a } \\
\text { good fit for their hospital? }\end{array}$ & $\begin{array}{l}\text { 5. [Ordinal] I believe that the ASOS-2 intervention is a good fit for my } \\
\text { hospital. 5-point Likert scale. } \\
\text { 6. [Ordinal] The ASOS-2 intervention is essential in providing appropriate } \\
\text { care for 'high-risk' surgical patients at my hospital. 5-point Likert scale. } \\
\text { (CFIR* Inner setting - tension for change) } \\
\text { 7. [Ordinal] The intervention fits well with existing work processes and } \\
\text { practices within our setting. 5-point Likert scale. (CFIR* Inner setting - } \\
\text { compatibility) } \\
\text { 8. [Ordinal] Compared to other possible programmes, the main ASOS-2 } \\
\text { Trial will have a high priority in my work. 5-point Likert scale. (CFIR* Inner } \\
\text { setting - relative priority) } \\
\text { 9. [Qualitative] Are there other interventions that you think would be } \\
\text { more appropriate to implement in order to prevent severe postoperative } \\
\text { complications and deaths? (CFIR* Intervention characteristic - relative } \\
\text { advantage) }\end{array}$ \\
\hline
\end{tabular}

Feasibility

Stakeholder level opinion about Do stakeholders think the the experience of the intervention intervention is useful and in their institution intervention is useful
sustainable at their hospital?

10. [Ordinal] The ASOS-2 intervention was useful at my hospital. 5-point Likert scale.

11. [Qualitative] Did you have sufficient resources to implement and administer at least two of the four components of the ASOS-2 intervention? If, no, what resources are needed to make this intervention possible at your hospital? (CFIR* Readiness - available resources)

12. [Ordinal] It is likely that I will be able to continue the intervention at my hospital if it shows benefit in the main ASOS-2 Trial. 5-point Likert scale. (CFIR* Individual characteristics - beliefs)

13. [Ordinal] The important key leaders and managers at my hospital were involved in the ASOS-2 Pilot Trial. 5-point Likert scale. (CFIR* Readiness - leadership involvement)

14. [Qualitative] Going forward, who are the key influential individuals at your hospital who need to be involved with the implementation of the ASOS-2 intervention? What is their position in the hospital? (CFIR* Process - engaging)

Fidelity

Stakeholder belief regarding adherence; integrity; and quality of program delivery
Do stakeholders believe the ASOS-2 intervention was implemented successfully at their hospital?
15. [Ordinal] I believe that the 'high-risk' patients truly received 'increased postoperative surveillance' compared to the care that they would normally have been given. 5 -point Likert scale.

16. [Qualitative] What is needed to ensure that patients truly receive 'increased postoperative surveillance'? 
Table 2. The ASOS-2 Trial processes

Whatsapp

Stakeholder opinion regarding utility of the intervention
Are stakeholders of the opinion the Whatsapp message system facilitated the pilot trial process?

17. [Ordinal] The ASOS-2 Pilot Trial would have been more difficult without the Whatsapp messaging support. 5-point Likert scale. (CFIR* Inner setting - tension for change)

18. [Ordinal] The Whatsapp messaging fits well with the running of the ASOS-2 Pilot Trial. 5-point Likert scale. (CFIR* Inner setting compatibility)

19. [Qualitative] What features would improve the use of the Whatsapp messaging in the ASOS-2 Trial?

Site initiation

Stakeholder opinion about the way their site participated in the pilot trial

Do stakeholders think their correct people were involved in running the pilot trial at their hospital?

20. [Ordinal] It was a simple process to involve the key leaders and stakeholder at my hospital in running the ASOS-2 pilot. 5-point Likert scale.

21. [Ordinal] We had a clear plan on how to involve the various key leaders and stakeholders at my hospital. 5-point Likert scale.

22. [Ordinal] It was easy to delegate the tasks involved in running the ASOS-2 Pilot Trial amongst the stakeholders at my hospital. 5-point Likert scale.

23. [Qualitative] What changes to the trial processes will make the main ASOS-2 Trial run smoother at your hospital?

Data collection

Stakeholder attitude towards the processes involved in collecting pilot data
Do stakeholders think the CRF screening form and REDCap tools were easy to use and appropriate for the pilot trial?
Trial participation

Stakeholder attitude to sustainable involvement in ASOS projects
Do stakeholders feel they can maintain the level of involvement that was required during the pilot in annual future projects?
24. [Ordinal] The case report form (CRF) was easy to follow. 5-point Likert scale.

25. [Ordinal] The documentation with video guidance was helpful fo understanding the CRF. 5-point Likert scale.

26. [Ordinal] The CRF manages to capture the important information without being too long. 5-point Likert scale.

27. [[Ordinal] Capturing the data onto REDCap was straightforward. 5-point Likert scale.

28. [Ordinal] We developed a simple way of keeping track of all eligible cases at my hospital. 5-point Likert scale.

29. [Qualitative] What improvements would you make to the CRF, screening record and REDCap database to make the work easier for the main ASOS-2 Trial?

30. [Ordinal] I/we have the capacity at the hospital to maintain my/our involvement with similar ASOS projects about once a year. 5-point Likert scale.

\footnotetext{
*CFIR is the Consolidated Framework for Implementation Research. https://cfirguide.org/
} 